\title{
A longitudinal study of functional unmet need among people with dementia
}

Sanna Read ${ }^{1}$, Bo Hu${ }^{1}$, Raphael Wittenberg ${ }^{1}$, Nicola Brimblecombe ${ }^{1}$, Louise Robinson ${ }^{2}$, Sube Banerjee ${ }^{3}$

${ }^{1}$ Care Policy and Evaluation Centre, London School of Economics and Political Science

2 Population Health Sciences Institute, Newcastle University

${ }^{3}$ Faculty of Health, University of Plymouth

${ }^{*}$ Contact details of the corresponding author:

Care Policy and Evaluation Centre

London School of Economics and Political Science

Houghton Street, London

WC2A 2AE, United Kingdom

Email: s.read@Ise.ac.uk

Running title: Unmet need in dementia 


\begin{abstract}
Background: Understanding the changes of unmet need in dementia may enable effective targeting of help and allow people to stay in their homes longer.

Objective: We investigated changes in unmet need and functioning over a 4-year period and the role of socio-demographic factors in these changes among people with dementia.
\end{abstract}

Methods: 234 community-dwelling people with dementia at baseline were studied in three consecutive waves (four years) of the English Longitudinal Study of Ageing (ELSA). Unmet needs (self/informant-reported limitations for which no help was received) and functional limitations (self/informant-reported difficulties in activities/instrumental activities of daily living and mobility) were modelled with latent growth curves. Sex, age, partnership and socioeconomic status at baseline were used as predictors. Admission to a care home was an additional outcome.

Results: Unmet needs increased over time, especially among those who initially had more functional limitations. Unmet needs contributed to faster decline in functional capability, except among those with many limitations initially. The major driver of increased unmet needs was not having a partner (direct effect). Age, sex and wealth contributed indirectly via the initial level of functional limitations and/or unmet need. Those with several functional limitations but few unmet needs were most likely to move to a care home.

Conclusions: Unmet need increases over time in those with dementia with mitigating effects of having a partner and initial levels of functioning. Meeting needs 
at early stages of dementia, especially for those living alone and when functional limitations are low may help slow functional decline.

Key words: needs, functional status, longitudinal survey, social inequalities, dementia 


\section{Introduction}

Dementia is a condition characterized by progressive cognitive impairment and functional limitation. Because of the progressive course of dementia, the person with dementia may become increasingly dependent in activities of daily living, which may lead to increased needs for care and support [1]. Support which is needed is not always available resulting in unmet need. This can occur since the caregiver or person with dementia may not recognise the need, the person with dementia may refuse care, or the care provided does not meet the quality or quantity needed due to problems with communication, decreased ability to care for oneself and ineffective use of resources[2]. Unmet need in dementia is common, a systematic review of the point prevalence of unmet need reported that over $90 \%$ of people with dementia have at least one caregiver-reported unmet need [3]. These unmet needs are often related to safety, health and medical care, daily activities, company, and counselling and legal support $[3,4]$. Unmet need is associated with individual characteristics such as lower socio-economic status and functional limitations. It has been reported to contribute to poorer general well-being, lower quality of life, and need for institutional care [5]. Although there is accumulating evidence on unmet needs in dementia and their causes and outcomes, the findings so far have been based on using regression methods often in cross-sectional settings $[3,4]$. To understand the processes of declining functioning, increasing needs, how changing needs are met, and the role of predictors and outcomes in these processes, a longitudinal approach is needed.

Unmet needs are not distributed equally. Some subgroups such as those without a partner and with low socioeconomic position experience more unmet 
needs [6-9]. Some studies have also found sex differences in unmet needs among people with dementia; in a Chilean study unmet needs were more frequent among men [8] whereas in a Polish study they were more frequent among women [10]. Unmet needs are also affected by functional limitations related to age and dementia itself and other co-occurring long-term conditions [11]. This interplay is complex: although unmet needs are more likely in the presence of numerous functional limitations, unmet needs may also occur when people have low levels of need or they do not fit into the stereotype of requiring care (e.g. younger age) [12]. In these cases, care needs may go unnoticed as they are not expected to need care or they do not ask for care. Having all needs met may benefit well-being but not necessarily improve the level of functioning. Whether unmet needs impact the trajectories of functioning or vice versa has not been studied longitudinally.

Trajectories of unmet needs may be slowed down or speeded up by various factors $[7,9]$, some of which are potentially modifiable (such as economic resources, living with someone who can help) and others not (such as age). The effects may be mediated through other factors in pathways, e.g. higher age is often associated with poorer functioning, which in turn is associated with higher level of unmet needs, e.g. see the stepwise regression in [7]. When using cross-sectional data, these pathways cannot be detected and mediation may go undetected. This may explain the mixed findings on predictors in cross-sectional studies using regression analyses. Examining associations between unmet need and functional limitations requires assessment of parallel processes which affect each other but may also interact (e.g. the effect may be different at low levels of a variable compared to high levels).

Understanding the factors in the pathways is important because the receipt of sufficient help in the presence of difficulties in everyday activities may allow people 
to live in the community longer and may enhance their quality of life $[13,14]$. In this study we therefore aimed to investigate longitudinal patterns of change in functional unmet needs among people with dementia including: the pathways of unmet needs; the impact of demographic and socioeconomic factors; and associations with outcomes (including care home admission). The research questions were:

1) How does unmet need change over time among people with dementia when changes in functioning are taken into account?

2) How do sociodemographic factors predict changes in unmet need among people with dementia?

3) Does unmet need predict functional limitations and care home admission among people with dementia?

\section{Methods}

Data

The research reported here is part of the DETERMIND programme [15] which aims to understand the determinants of quality of life, care and costs and the consequences of inequalities in people with dementia and their carers. Our sample for this study was drawn from the English Longitudinal Study of Ageing (ELSA), a nationally representative longitudinal study of the older (aged 50+) household population of England [16]. The first wave of ELSA was conducted in 2002-2003 and consecutive waves were carried out every two years. The description of sampling and data collection is reported elsewhere [17]. Our analysis is based on data collected at waves 6, 7, 8 and 9 conducted in 2012-3, 2014-15, 2016-17 and 201819, respectively. These waves were selected because they included detailed 
questions on needs for and receipt of social care which were used to determine unmet need. The sample in the current study included those aged 50+ living in the community at baseline, and identified as having dementia using self-reported or informant-reported ( $43 \%$ reported by an informant) physician diagnosis of dementia or Alzheimer's disease or Informant Questionnaire on Cognitive Decline in the Elderly (IQCODE) informant reports of change in behaviour and cognition (score 3.5 or more) [18]. To maximise statistical power, we included all those identified in wave $6(n=164)$ and new cases identified in wave $7(n=71)$, and followed them up over four years (waves 6, 7 and 8 or waves 7, 8 and 9). 70 individuals were excluded because they were living in care homes at baseline. Participants gave their written informed consent to take part in ELSA. Ethical approval for ELSA was given by the London Multicentre Research Ethics Committee.

\section{Measures}

\section{Unmet need}

In ELSA unmet needs were measured using self or informant reports (about $33 \%$ reported by an informant). The information for identifying unmet need (whether the participant had functional difficulties, i.e. needs, and whether they received help for them) was available for 13 tasks: five Activities of Daily Living (ADLs), four Instrumental Activities of Daily Living (IADLs) and four mobility items (see Supplementary Table 1). A more detailed description of the measure for unmet need and its use in ELSA can be found elsewhere [19]. ADLs comprised difficulty with: dressing; bathing or showering; eating; getting in and out of bed; and using the toilet. The IADLs were difficulty with: shopping for groceries; taking medication; doing work around the house or garden; and managing money. Mobility limitations were difficulty 
with: walking 100 yards (91.44 metres); climbing several flights of stairs without resting; climbing one flight of stairs without resting; and walking across a room. Where ADL, IADL or mobility difficulties were experienced, participants were asked about receipt of help [19]. If participants reported difficulty conducting any of these activities but did not receive help for that activity, the item was coded an unmet need $(0=$ received help for the respective need, $1=$ did not receive help for the respective activity). For those who scored 1 in any of these unmet need variables, the number of activities for which the need was not met was calculated.

\section{Functional limitations}

The number of functional limitations was used to measure the severity of functional disability. All 25 items of self- or informant-reported ADL, IADL and mobility limitations available in the dataset were used. Supplementary Table 1 shows the detailed list of the items. Each item was binary: $0=$ no difficulty, $1=$ difficulty reported. The items for ADLs, IADLs and mobility were highly correlated (the correlations between the three subscales varied between 0.52 and 0.68 ) and using a total count showed good internal consistency (Cronbach's alpha $=0.94,0.94$ and 0.96 for the three time points).

\section{Socio-demographic factors}

Age was measured in years. Sex and whether the participant had a partner were binary variables. A binary measure was also used for educational level, contrasting having any qualification (college or university diploma or degree, $\mathrm{O}^{\prime}$ or $\mathrm{A}^{\prime}$ levels or equivalent public examinations taken in secondary schools at around ages 16 and 18 respectively or vocational or foreign qualifications) with having no 
qualifications. Routine occupation was based on the National Statistics Socioeconomic Classification (NS-SEC) classification divided into two groups: higher managerial, administrative and professional or intermediate occupations; and routine and manual occupations [20]. Wealth quintiles were calculated using non-pension wealth comprising financial, physical and housing wealth net of debt. Wealth quintile was treated as linear scale in the analysis. Home ownership was a binary measure, divided into those owning their home outright or with mortgage or shared-ownership, and those renting, living rent free, or squatting. The sociodemographic information was reported by the participant or informant.

\section{Admission to a care home}

Information on whether the participant was living in a care home at the point of the interview was based on their recorded place of residence, reported either by themselves or by an informant. The information on care home admission was missing if neither the person nor an informant could be contacted.

\section{Analysis}

We used Latent Growth Curve modeling to examine the level and change in unmet need and functional limitations and their associations with socio-demographic factors. In a Latent Growth Curve model [21], random effects are used to capture individual differences and fixed effects to estimate the average growth of the entire sample. Analyses were carried out using Mplus 8 [22]. Three time points were used to estimate the initial level (intercept) and linear change (slope) in unmet need and functional limitations. The sociodemographic variables were included as potential predictors of the level and change of unmet need and functional limitation (see the 
pathways in Figure 1). This allowed us to assess mediation, the mechanisms that link the predictors to changes in unmet need, in this case mediation through the baseline levels of unmet need and functional limitations. Indirect effects were standardized to make it easier to compare the effect sizes [23].

We also tested the effect of interaction between the level of unmet need and functional limitations on change in these two variables. This was to investigate to what extent functional limitations at baseline moderate the relationships between unmet needs at baseline and subsequent changes in unmet need and functional limitations. Mediation and interaction were assessed in different models, because it is not possible to calculate indirect mediation effects when an interaction term is included.

The fit of the model was assessed by chi square analysis, but because this index is sensitive to sample size we also used three other fit indices as recommended by $\mathrm{Hu}$ and Bentler [24] and Kline [25]: the Comparative Fit Index (CFI), Root Mean Square Error of approximation (RMSEA) and Standardized Root Mean Square Residual (SRMR). A value at or below 0.08 for the RMSEA and SRMR, and at or above 0.90 for the CFI was considered to indicate an adequate fit for the model. Maximum likelihood estimation with robust standard errors (MLR) was used to take into account any non-normality in the sample. Missing data were handled using the full information maximum likelihood method (FIML) [26]. This method makes it possible to estimate the likelihood function for all cases based on the information on the means and variances of the variables that are present in the dataset.

\section{Results}




\section{Descriptive data}

Table 1 shows the distributions of the variables. About half of the sample were women (52\%). The average age was 78 years. Sixty percent had a partner. Almost half reported no formal qualifications (48\%) and a routine occupation as their last job (45\%). The majority of the participants were home owners (75\%). The participants had on average two unmet needs (range 0-13) and 11 functional limitations (range 124) at baseline. The number of unmet needs tended to increase slightly over time, while the number of functional limitations did not change. This pattern is likely to depict selection due to attrition, as it ignores the impact of sample attrition. The estimated means (the last column in Table 1), however, use all available information to estimate the parameters including incomplete data from those who drop out or die. These estimated means that adjust for attrition showed increases over time in both unmet needs and functional limitations. Functional limitations in IADLs were most common (mentioned by over $50 \%$ ) while climbing several flights of stairs without resting was a frequently mentioned mobility difficulty (mentioned by $71 \%$ ) (Supplementary Figure 1). Unmet needs were frequent in mobility tasks and some IADLs.

The number of participants halved between consecutive time points. Around two-thirds of participants (65\%) dropped out over the four year period between time points 1 and 3 , while $24 \%$ of the original sample remained living in the community and participated in all three waves and $11 \%$ moved to care homes between times 1

and 3. Because there was no information on the reasons for drop-out (some may have entered care homes), all those who dropped out were treated as missing in the additional analysis where admission to a care home was the outcome variable. 
Those who dropped out or moved to care homes were characterised by older age and poorer functioning but fewer unmet needs at baseline compared to those who remained in the sample throughout the waves both in bivariate and multinomial models (see Supplementary Table 1). In the bivariate analyses, those who moved to care homes were more likely to be women and those who dropped out were less likely to have a partner or qualifications compared to those who participated in all waves. These associations however disappeared when all predictors were included in the multinomial model.

Table 2 shows the bivariate correlations between the variables. Unmet need was associated with not having a partner and a number of socio-economic variables, including not being a home owner and lower wealth quintile. Functional limitations were associated with older age, not having a partner and lower socioeconomic status. Unmet need correlated with higher frequency of functional limitations. The concurrent correlations between unmet need and functional limitations grew stronger over the three time points. Functional limitations at time 1 predicted unmet needs over the three time points whereas time 1 unmet need was a poorer predictor for functional limitations over the consecutive time points.

\section{Latent Growth Curve data}

Level and change in unmet need and functional limitations

We fitted the model shown in Figure 1. The model fitted the data well $\left(\chi^{2}=\right.$ 40.30, $\mathrm{df}=22, p=0.010, \mathrm{CFI}=0.94, \mathrm{RMSEA}=0.060, \mathrm{SRMR}=0.061)$. People with dementia were estimated to have two unmet needs (parameter estimates for the intercept of level $=2.00, \mathrm{SE}=0.134, p<0.001)$ and 11 functional limitations at baseline (parameter estimates for the intercept of level 11.1, SE $=0.426, p<0.001$ ). 
The intercepts for growth showed that during the four-year follow-up, people with dementia gained on average 0.7 new unmet needs (estimate $=0.73$, SE $=0.222, p<$ 0.01 ) and four new functional limitations (estimate $=4.10, \mathrm{SE}=0.811, p<0.001$ ). The residual variances indicated that there was considerable variation around the initial level of unmet need (estimate $=2.57, \mathrm{SE}=0.974, p<0.01$ ) and functional limitations (estimate $=39.02, \mathrm{SE}=3.844, p<0.001$ ). However, there was no evidence of significant individual variation around the sample mean (residual variance for growth in unmet need $=0.26$, SE $=0.175, p \geq 0.05$; residual variance for growth in functional limitations $=3.22, \mathrm{SE}=1.954, p \geq 0.05)$.

Figure 1 shows that the initial level of functional limitations predicted the growth in unmet need. On average, for those with 11 functional limitations the number of unmet needs increased by 0.7 over four years. However, if an individual initially had only 5 functional limitations for example, the growth in unmet need was 0.34 new unmet needs, while an individual with 17 functional limitations initially had 1.4 new unmet needs after four years. This pattern of faster increase in unmet needs at higher baseline levels of functional limitation (i.e. fanning out) is depicted in Figure 2. In comparison, a higher initial level of unmet need predicted less growth in unmet need and functional limitations over the four-year period (i.e. fanning in). The associations between the baseline level of unmet need and change in unmet need are presented in Figure 3. The associations between baseline unmet need and change in functional limitations varied by the level of functional limitations. The results for the interaction are given below.

We tested the effect of the interaction between the level of unmet need and functional limitations on the change in these two variables. The interaction terms were added to the model shown in Supplementary Figure 2. The results showed that 
the initial level of functional limitations modified the association between unmet need and change in functional limitations (the estimate for the interaction term $=0.043, \mathrm{SE}$ $=0.015, p<0.01)$. Figure 4 illustrates the trajectories of functional limitations by the initial level of unmet needs and functional limitations. At lower levels of functional limitations (solid lines), an initially lower number of unmet need (light grey) was associated with slower increase in functional limitations over the four-year period compared to those who had higher levels of unmet need (dark grey). At higher initial levels of functional limitations (dashed lines), the increase in functional limitations was very small among both those with lower (light grey) and those with higher levels (dark grey) of unmet needs at baseline. There was no interaction between the initial levels of unmet need and functional limitation to change in unmet need.

The associations of socio-demographic variables with level and change of unmet need

Figure 1 shows that, apart from the direct effect of having a partner on change in unmet need, all other effects from the socio-demographic factors to change in unmet need run through the level of unmet need and functional limitations. Table 3 shows the indirect effects from higher age and lower wealth through higher level of functional limitations to faster increase in unmet need. Female sex and higher wealth contributed to faster increase in unmet need through the level of unmet need. For sex and wealth, the various indirect effects cancelled each other out, resulting in non-significant total indirect effect. All the indirect effects on change in unmet need were small, with the standardized estimates varying between 0.01 to 0.15 .

The association between unmet need and moving to a care home 
We added care home admission as an outcome to the latent growth curve model and included the interaction between baseline level of unmet need and functional limitations (Supplementary Figure 3). The interaction term predicted move to a care home (estimate $=-0.01, \mathrm{SE}=0.002, p<0.05$ ). Both independent effects were also significant: a lower level of unmet need (estimate $=-0.07, \mathrm{SE}=0.035, p<$ 0.05 ) and a higher level of functional limitations (estimate $=0.038, \mathrm{SE}=0.009, p<$ 0.001) predicted move to a care home. The results showed that at lower levels of functional limitations a higher number of unmet needs was associated with a lower likelihood of moving to a care home whereas among those with fewer unmet needs admission to a care home was more likely, see Supplementary Figure 4. At higher levels of functional limitation, the baseline level of unmet need did not make any difference to the likelihood of moving to a care home.

Sensitivity analysis for the subcategories of unmet need

We carried out a further analysis using the three subcategories of unmet need related to mobility, ADLs and IADLs. This was done to check if the pattern of change over time and the association with functional limitations were similar for the subcategories. Supplementary Table 2 shows the observed means and estimated intercept and slope for the unmet needs related to mobility, ADLs and IADLs. Mobility and IADL related unmet needs appeared to increase according to the observed means. The latent growth curve modelling showed that the increasing trend (slope) was significant: the person with dementia gained approximately 0.5 new unmet mobility needs and 0.4 new unmet IADL needs over the four-year period. There was no change in unmet needs related to ADLs. 
When these subcategories of unmet needs were used instead of the total unmet need score in the full latent growth curve model, the model for mobility and IADL related unmet needs were very similar to the model for total unmet need score shown in Figure 1. However, neither the intercept of unmet need related to mobility nor that related to IADL tasks was associated with the slope of functional limitation (likely due to the reduced power in the model when using subcategories).

\section{Discussion}

Our study is, to the best of our knowledge, the first to investigate longitudinal patterns of change in functional unmet needs among people with dementia. We found that in people with dementia unmet needs increase over time and that the main drivers were not having a partner and a higher number of functional limitations at baseline (direct effects). Age, female sex and wealth acted indirectly through a number of paths. It is of interest that those with fewest unmet needs at baseline, paradoxically had the greatest increase in unmet needs over time. Most strikingly the more needs were met at baseline the slower was the rate of functional decline, and having a higher level of unmet need predicted faster functional decline. This suggests possibilities that actions to identify and address needs early in the illness may slow loss of functional ability in dementia. 
We found that unmet needs, especially those related to IADLs and mobility, increased over time among people with dementia, and this increase was faster among those with higher numbers of functional limitations at baseline. Although there was considerable variation between the individuals in baseline levels of unmet need and functional limitations, the direction of change - both unmet needs and functional limitations increased over the four-year period - was uniform across the sample. This is not surprising as dementia is characterised by declining functional ability and increasing need for help $[1,27]$. However, it is of interest that we found that unmet needs increased faster over time when the baseline level of unmet needs was lower. The result is not surprising since the potential for change is higher when the starting level is low, compared to when it is high (ceiling effect) There could be some convergence to the mean, if those reporting a high (low) number of unmet needs at baseline were experiencing an especially difficult (relatively less difficult) period at the time, such as waiting for services to start. Additionally, it could be that attrition reduced the opportunity to detect the full range of variation. However, our models did take into account attrition over time and two-way effects between processes in unmet needs and functional limitations.

The impact of the interaction between the baseline level of unmet need and functional limitations on the change in functional limitations illustrates the complexity of the association: those with low or medium levels of functional limitations initially experienced a slower increase in functional limitations over time if they reported a lower number of unmet needs. This suggests that having needs met was associated with a slower rate of functional decline. However, having a higher level of unmet need predicted faster functional decline. Some previous findings in cross-sectional studies show that people at the early stages of dementia with only few functional 
limitations are less likely to receive sufficient help [6] and consequently may experience poorer quality of life. Our findings suggest that in these groups having a higher number of unmet needs may also have detrimental effects on future functional decline. It is possible that at higher levels of functional limitations (needs) the receipt of help or lack of it has less effect on the overall progression of functional limitations [28].

The difference in results at lower and higher levels of functional limitations and unmet needs may also reflect that unmet need may have a different meaning or content at different levels of functional limitations. There could also be differences in perception or reporting of help received at different levels of ability to conduct ADL, IADL or mobility tasks with under- or over-reporting in specific groups. Investigating further the profiles of individual unmet needs and functional limitations would be useful, with more granular data and a larger sample size.

\section{Change in unmet needs and sociodemographic factors}

Apart from the effect of having a partner on reduced unmet need over the four-year period, none of the other sociodemographic factors had a direct association with change in unmet need. Age and wealth effects on increased unmet needs were mediated through the level of functional limitations, while the effects of female sex and of higher wealth were mediated through the level of unmet need increasing the unmet needs. The effect sizes of mediation were relatively small: the standardized estimates did not exceed 0.15 . Moreover, when the indirect contributions through the levels of unmet need and functional limitations were taken into account, they often counteracted resulting in near zero total indirect effect. Living alone has been found to be associated with better functioning and use of more 
services in mild to moderate dementia[29]. Moreover, previous studies have shown that people living with a partner have a lower level of unmet needs $[6,7,9]$. The current study did not find an association between the level of functioning or level of unmet need and having a partner. However, our study suggests that living with a spouse or partner slows down the increase in unmet needs (and functional limitations), which underscores the vital role of family caregivers to the wellbeing of older people with dementia. The results also suggest that factors, such as higher socioeconomic status, found to be associated with unmet needs in previous crosssectional studies [6-9] predicted lower levels of unmet needs but their contribution to limiting the increase in unmet needs over time is less clear.

Unmet need and move to a care home

Although previous evidence shows that higher levels of unmet needs are associated with admission to care homes [5], the results from the current study did not find this association. We found that high levels of functional limitation, combined with a low number of unmet needs, predicted higher likelihood of admission to a care home, compared to those with more unmet needs. The differences between the current study and previous work may be due to different follow-up periods. The current study used relatively long follow-up of four years compared to the shorter follow up of 18 months in a previous study [5]. A longer follow-up may increase the chance of picking up the institutionalisation of those people with dementia who remained in the community longer and might have had a profile of functional limitations in which lack of receipt of help was not critical in continuing to live at home. It should be noted that in ELSA move to a care home was recorded only if the participant or informant reported a care home as the participant's current place of 
residence. It is possible that some people had moved to a care home and died between the ELSA waves or had moved to a care home and dropped out of the study with no informant information available.

\section{Limitations}

The study has important limitations. First, the dataset did not include measures of neuropsychiatric symptoms or severity of dementia. The number of limitations in ADL and IADL rises with severity of dementia, so the inclusion in the model of functional limitations means that severity of dementia is taken into account indirectly at least partially, but some functional problems may be unrelated to dementia, but reflect aging or other comorbidities. Further longitudinal research is needed which includes direct measures of the severity of dementia and important comorbidities such as neuropsychiatric symptoms. Second, unmet needs were measured using the 13 items included in ELSA, which tap unmet needs in ADLs, IADLs and mobility. The ELSA unmet needs score differs from measures used in other studies for investigating unmet need. For instance, the ELSA data does not permit assessment of some dimensions of unmet needs examined in previous studies, such as unmet needs for medical care [30], counselling, social integration, dementia diagnosis and treatment [6], or psychological or behavioural factors $[31,32]$. The receipt of help questions did not ask whether the help received was appropriate or met the need. In addition, it was not possible to link the information on equipment use for mobility limitations with the specific need questions. Third, the identification of dementia in ELSA was not based on direct clinical assessment but on self- or informant-reported physician diagnosis or informant-reported change in memory and behaviour over the last two years. The IQCODE questionnaire is robust 
and widely used, but it is possible that dementia was underestimated, because participants or informants did not disclose it or did not know it. Fourth, those with cognitive problems are more likely to have dropped out of the study, affecting the numbers participating in successive waves of ELSA and limiting the ability to model complex mediation. Fifth, the reports of those with cognitive impairment may be subject to greater error than those with intact cognition. In ELSA, informant interviews were used when the participant was not able to answer the questions (i.e. at later stages of dementia). The different sources of information may result in differences in reporting the needs and receipt of help. At the early stages of dementia, self-ratings have been found to be more closely correlated with objectively assessed functioning compared to proxy ratings [33]. Sixth, especially in a sample with high levels of needs, using binary measures for functional limitation may result in a ceiling effect as there is no opportunity to measure the gradient of the severity of each functional difficulty.

Finally, information on admission to a care home was available only if inperson or informant interview was possible. Some participants who dropped out might have entered care home but there was no information on this. The proportion of those living in a care home identified in ELSA is somewhat lower than expected among people with dementia; in the current study, $29 \%$ were reported to live in a care home at the baseline compared to $39 \%$ on average in the United Kingdom [34]. Modelling with full information maximum likelihood made it possible to retain cases where information on outcomes (such as care home admission) was missing. However, the number of care home admissions was low and could be an underrepresentation of admissions among people who lived alone before care home admission and for whom no informant information was available. In addition our 
ability to interrogate factors influencing care home admission is limited by the relative lack of measurement of social rather than functional need.

Implications for practice and future research

A key message from our findings for health and social care practitioners is the implications for those with dementia who live alone. Our data quantify their vulnerability in terms of higher levels of unmet needs and a faster rate of functional decline. This makes clear the need for memory assessment services and postdiagnostic care services to focus on early assessment and effective tailored intervention in this group. The vulnerability of this group has been identified but there is a need for further research on specific community support interventions for them $[35,36]$. Overall the finding that higher levels of unmet need predict faster functional decline provides support for services that identify and address needs early in the illness for all those with dementia. The possibility that such intervention may slow Ioss of functional ability in dementia requires further research. In terms of the focus of unmet need in people with dementia in general, a recent scoping review including 27 studies from 11 high income countries, found a wide range, encompassing emotional, medical, financial, social, personal and safety needs [4]. Unfortunately the review also found considerable variation in the quantity, quality and flexibility of services to address such unmet demand. Measurement and identification of need in people with dementia is a complex task requiring professional skills. There are a number of systems and instruments available to help this process, but it is not clear which work best. Informant report by carers may be easier to undertake than selfreport from people with dementia [4] but there are issues when there is no carer available. Further research exploring which is the most effective, acceptable and 
feasible for professionals to use in practice, especially in community settings, would be helpful.

Conclusions

Our study illustrates that among people with dementia the number of unmet needs increases over time. The major drivers of increased unmet needs were not having a partner and a higher number of functional limitations at baseline. Meeting the needs at the early stages of dementia when functional limitations are not yet high may be protective of functional decline in the future. In terms of implications for clinical practice, attention should be paid to identifying the unmet needs of people with dementia, especially those who live alone, and the factors that can reduce unmet needs. 


\section{Acknowledgements:}

This work was supported by the Economic and Social Research Council (UK) and the National Institute for Health Research (UK), Grant/Award Number:

ES/S010351/1. The funding bodies did not have any role in the design of the study and collection, analysis, interpretation of data and in writing the manuscript.

\section{Conflict of interest declaration:}

The authors have no conflict of interest to report. 


\section{References}

[1] Janssen O, Vos SJB, Handels R, Vermunt L, Verheij R, Verhey FRJ, van Hout H, Visser PJ, Joling KJ (2020) Duration of Care Trajectories in Persons With Dementia Differs According to Demographic and Clinical Characteristics. J Am Med Dir Assoc 21, 1102-1107.e6.

[2] Cohen-Mansfield J, Dakheel-Ali M, Marx MS, Thein K, Regier NG (2015) Which unmet needs contribute to behavior problems in persons with advanced dementia? HHS Public Access. Psychiatry Res 228, 59-64.

[3] Curnow E, Rush R, Maciver D, Górska S, Forsyth K (2021) Exploring the needs of people with dementia living at home reported by people with dementia and informal caregivers: a systematic review and Meta-analysis. Aging Ment Heal 25, 397-407.

[4] Morrisby C, Joosten A, Ciccarelli M (2018) Do services meet the needs of people with dementia and carers living in the community? A scoping review of the international literature. Int Psychogeriatrics 30, 5-14.

[5] Gaugler JE, Kane RL, Kane RA, Newcomer R (2005) Unmet care needs and key outcomes in dementia. J Am Geriatr Soc 53, 2098-2105.

[6] Black BS, Johnston D, Rabins P V., Morrison A, Lyketsos C, Samus QM (2013) Unmet needs of community-residing persons with dementia and their informal caregivers: Findings from the maximizing independence at home study. J Am Geriatr Soc 61, 2087-2095.

[7] Black BS, Johnston D, Leoutsakos J, Reuland M, Kelly J, Amjad H, Davis K, Willink A, Sloan D, Lyketsos C, Samus QM (2019) Unmet needs in communityliving persons with dementia are common, often non-medical and related to patient and caregiver characteristics. Int Psychogeriatrics 31, 1643-1654. 
[8] Zhou Y, Slachevasky A, Calvo E (2018) Health conditions and unmet needs for assistance to perform activities of daily living among older adults with dementia in Chile. Int J Geriatr Psychiatry 33, 964-971.

[9] Zhang J, Xu X, Yang LM, Wang J (2021) Met and unmet care needs of homeliving people with dementia in China: An observational study using the Camberwell Assessment of Need for the Elderly. Geriatr Gerontol Int 21, 102107.

[10] Mazurek J, Szcześniak D, Urbańska K, Dröes R-M, Rymaszewska J (2017) Met and unmet care needs of the elderly with dementia living at home: Personal and informal carers' perspectives. Dementia 18, 1963-1975.

[11] Blaum CS, Ofstedal MB, Liang J (2002) Low cognitive performance, comorbid disease, and task-specific disability: Findings from a nationally representative survey. Journals Gerontol - Ser A Biol Sci Med Sci 57, 523-531.

[12] Harling G, Payne CF, Davies JI, Gomez-Olive FX, Kahn K, Manderson L, Mateen FJ, Tollman SM, Witham MD (2020) Impairment in Activities of Daily Living, Care Receipt, and Unmet Needs in a Middle-Aged and Older Rural South African Population: Findings From the HAALSI Study. J Aging Health 32, 296-307.

[13] Beach SR, Schulz R, Friedman EM, Rodakowski J, Martsolf RG, James AE (2020) Adverse Consequences of Unmet Needs for Care in High-Need/HighCost Older Adults. Journals Gerontol Ser B 75, 459-470.

[14] Janssen N, Handels RL, Sköldunger A, Woods B, Jelley H, Edwards RT, Orrell M, Selbæk G, Røsvik J, Gonçalves-Pereira M, Marques MJ, Zanetti O, Portolani E, Irving K, Hopper L, Meyer G, Bieber A, Stephan A, Kerpershoek L, Wolfs CAG, de Vugt ME, Verhey FRJ, Wimo A (2018) Impact of Untimely 
Access to Formal Care on Costs and Quality of Life in Community Dwelling People with Dementia. J Alzheimer's Dis 66, 1165-1174.

[15] Farina N, Hicks B, Baxter K, Birks Y, Brayne C, Dangoor M, Dixon J, Harris PR, Hu B, Knapp M, Miles E, Perach R, Read S, Robinson L, Rusted J, Stewart R, Thomas A, Wittenberg R, Banerjee S (2020) DETERMinants of quality of life, care and costs, and consequences of INequalities in people with Dementia and their carers (DETERMIND): A protocol paper. Int J Geriatr Psychiatry 35, 290-301.

[16] Steptoe A, Breeze E, Banks J, Nazroo J (2013) Cohort profile: The English Longitudinal Study of Ageing. Int J Epidemiol 42, 1640-1648.

[17] Marmot M, Banks J, Blundell R, Lessof C, Nazroo J (2003) Health, wealth and lifestyles of the older population in England: ELSA 2002, Institute for Fiscal Studies, London.

[18] Cadar D, Lassale C, Davies H, Llewellyn DJ, Batty GD, Steptoe A (2018) Individual and Area-Based Socioeconomic Factors Associated With Dementia Incidence in England: Evidence From a 12-Year Follow-up in the English Longitudinal Study of Ageing. JAMA Psychiatry 75, 723-732.

[19] Vlachantoni A, Shaw R, Willis R, Evandrou M, Falkingham J, Luff R (2011) Measuring unmet need for social care amongst older people. Popul Trends $145,56-72$.

[20] Rose D, Pevalin DJ (2003) A researcher's guide to the national statistics socioeconomic classification, Sage Publications.

[21] Meredith W, Tisak J (1990) Latent curve analysis. Psychometrika 55, 107-122.

[22] Muthén LK, Muthén BO Mplus User's Guide, Muthén \& Muthén, Los Angeles, CA. 
[23] Cheung MWL (2009) Comparison of methods for constructing confidence intervals of standardized indirect effects. Behav Res Methods 41, 425-438.

[24] Hu LT, Bentler PM (1999) Cutoff criteria for fit indexes in covariance structure analysis: Conventional criteria versus new alternatives. Struct Equ Model 6, 155.

[25] Kline RB (2005) Principles and Practice of Structural Equation Modelling, The Guilford Press, New York.

[26] Acock AC (2005) Working with missing values. J Marriage Fam 67, 10121028.

[27] Farias ST, Chou E, Harvey DJ, Mungas D, Reed B, DeCarli C, Park LQ, Beckett L (2013) Longitudinal trajectories of everyday function by diagnostic status. Psychol Aging 28, 1070-1075.

[28] Hu B, Li L (2020) The protective effects of informal care receipt against the progression of functional limitations among chinese older people. Journals Gerontol - Ser B Psychol Sci Soc Sci 75, 1030-1041.

[29] Clare L, Martyr A, Henderson C, Gamble L, Matthews FE, Quinn C, Nelis SM, Rusted J, Thom J, Knapp M, Hart N, Victor C (2020) Living Alone with Mild-ToModerate Dementia: Findings from the IDEAL Cohort. J Alzheimer's Dis 78, $1207-1216$

[30] Eichler T, Thyrian JR, Hertel J, Richter S, Wucherer D, Michalowsky B, Teipel S, Kilimann I, Dreier A, Hoffmann W (2016) Unmet Needs of CommunityDwelling Primary Care Patients with Dementia in Germany: Prevalence and Correlates. J Alzheimer's Dis 51, 847-855.

[31] Miranda-Castillo C, Woods B, Galboda K, Oomman S, Olojugba C, Orrell M (2010) Unmet needs, quality of life and support networks of people with 
dementia living at home. Health Qual Life Outcomes 8, 1-14.

[32] Tapia Muñoz T, Slachevsky A, León-Campos MO, Madrid M, Caqueo-Urízar A, Rohde GC, Miranda-Castillo C (2019) Predictors of unmet needs in Chilean older people with dementia: a cross-sectional study. BMC Geriatr 19, 106.

[33] A M, L C (2018) Awareness of functional ability in people with early-stage dementia. Int J Geriatr Psychiatry 33, 31-38.

[34] Prince M, Knapp M, Guerchet M, McCrone P, Prina M, Comas-Herrera A, Wittenberg R, Adelaja B, Hu B, King D, Rehill A, Salimkumar D (2014) Dementia UK: Second Edition - Overview, Alzheimer's Society.

[35] Eichler T, Hoffmann W, Hertel J, Richter S, Wucherer D, Michalowsky B, Dreier A, Thyrian JR (2016) Living Alone with Dementia: Prevalence, Correlates and the Utilization of Health and Nursing Care Services. $J$ Alzheimer's Dis 52, 619-629.

[36] Evans D, Price K, Meyer J (2016) Home Alone With Dementia. SAGE Open 6, $1-13$ 
Table 1. Descriptive and socio-demographic variables at time 1 (ELSA wave 6 or 7), and unmet need, functional limitations and admission to care home at time 1, 2 and 3 (ELSA waves 6,7 and 8 or 7, 8 and 9) among people with dementia.

$n \quad \mathrm{M}(\mathrm{SD}) / \% \quad$ LGC Model

estimated means

\begin{tabular}{|c|c|c|c|}
\hline \multicolumn{4}{|l|}{ Sex } \\
\hline Female & 122 & 52 & - \\
\hline Total & 234 & 100 & - \\
\hline Age & 234 & $78.4(9.5)$ & - \\
\hline \multicolumn{4}{|l|}{ Has partner } \\
\hline Yes & 141 & 60 & - \\
\hline Total & 234 & 100 & - \\
\hline \multicolumn{4}{|l|}{ Qualification } \\
\hline No & 107 & 48 & - \\
\hline Total & 224 & 100 & - \\
\hline \multicolumn{4}{|l|}{ Routine occupation } \\
\hline Yes & 97 & 45 & - \\
\hline Total & 216 & 100 & - \\
\hline \multicolumn{4}{|l|}{ Home owner } \\
\hline Yes & 172 & 75 & - \\
\hline Total & 230 & 100 & - \\
\hline Wealth quintile & 209 & $2.7(1.2)$ & - \\
\hline Unmet need ${ }^{\mathrm{a}}$, time 1 & 214 & $2.1(2.2)$ & 2.0 \\
\hline Unmet need ${ }^{\mathrm{a}}$, time 2 & 105 & $2.2(2.2)$ & 2.3 \\
\hline Unmet need ${ }^{\mathrm{a}}$, time 3 & 53 & $2.3(1.9)$ & 3.2 \\
\hline Functional limitations ${ }^{\mathrm{b}}$, time 1 & 234 & $11.1(7.0)$ & 11.1 \\
\hline Functional limitations $^{\mathrm{b}}$, time 2 & 134 & $11.4(8.0)$ & 13.4 \\
\hline
\end{tabular}


Functional limitations $^{\mathrm{b}}$, time 3

Participation between time 1-3

Participated and living in community in all

three waves

Moved to care home

26

11

Dropped out

151

65

Total

234

100

\footnotetext{
${ }^{a}$ Number of ADL, IADL or mobility difficulties (max 13 items) in which does not receive help.

${ }^{b}$ Number of $A D L, I A D L$ and mobility limitations (max 25 items). M=mean, SD=standard deviation, LGC=Latent Growth Curve
} 
Table 2. Correlations ( $n$ in parenthesis) between socio-demographic variables (time 1, ELSA wave 6 or 7 ), unmet need, functional limitations and moving to care home (times 1-3, ELSA waves 6-8 or 7-9) among people with dementia in ELSA.

\begin{tabular}{|c|c|c|c|c|c|c|c|c|c|c|c|c|c|}
\hline & 1 & 2 & 3 & 4 & 5 & 6 & 7 & 8 & 9 & 10 & 11 & 12 & 13 \\
\hline 1 Female & - & - & - & - & - & - & - & - & - & - & - & - & - \\
\hline 2 Age & $\begin{array}{c}0.12 \\
(234)\end{array}$ & - & - & - & - & - & - & - & - & - & - & - & - \\
\hline 3 Partner & $\begin{array}{l}-0.34^{a} \\
(234)\end{array}$ & $\begin{array}{l}-0.31^{a} \\
(234)\end{array}$ & - & - & - & - & - & - & - & - & - & - & - \\
\hline 4 No qualification & $\begin{array}{c}0.10 \\
(224)\end{array}$ & $\begin{array}{c}0.16^{c} \\
(224)\end{array}$ & $\begin{array}{l}-0.23^{a} \\
(224)\end{array}$ & - & - & - & - & - & - & - & - & - & - \\
\hline 5 Routine occupation & $\begin{array}{r}0.04 \\
(216)\end{array}$ & $\begin{array}{l}-0.10 \\
(216)\end{array}$ & $\begin{array}{l}-0.08 \\
(216)\end{array}$ & $\begin{array}{c}0.52^{a} \\
(210)\end{array}$ & - & - & - & - & - & - & - & - & - \\
\hline 6 Home owner & $\begin{array}{l}-0.03 \\
(230)\end{array}$ & $\begin{array}{c}0.10 \\
(230)\end{array}$ & $\begin{array}{c}0.29^{a} \\
(230)\end{array}$ & $\begin{array}{l}-0.19^{b} \\
(220)\end{array}$ & $\begin{array}{l}-0.24^{a} \\
(212)\end{array}$ & - & - & - & - & - & - & - & - \\
\hline 7 Wealth quintile & $\begin{array}{l}-0.11 \\
(209)\end{array}$ & $\begin{array}{c}0.23^{b} \\
(209)\end{array}$ & $\begin{array}{l}0.31^{a} \\
(209)\end{array}$ & $\begin{array}{l}-0.19^{b} \\
(205)\end{array}$ & $\begin{array}{l}-0.34^{a} \\
(200)\end{array}$ & $\begin{array}{l}-0.41^{a} \\
(206)\end{array}$ & - & - & - & - & - & - & - \\
\hline 8 Unmet need $\mathrm{t} 1$ & -0.06 & -0.04 & -0.12 & 0.03 & 0.13 & $-0.20^{b}$ & $-0.22^{b}$ & - & - & - & - & - & - \\
\hline
\end{tabular}




\begin{tabular}{|c|c|c|c|c|c|c|c|c|c|c|c|c|c|}
\hline & $(214)$ & $(214)$ & $(214)$ & $(207)$ & (199) & $(210)$ & $(196)$ & & & & & & \\
\hline 9 Unmet need t2 & $(105)$ & $(105)$ & $(105)$ & $(100)$ & (97) & $(105)$ & (97) & (95) & & & & & \\
\hline \multirow[t]{2}{*}{10 Unmet need $\mathrm{t} 3$} & -0.05 & 0.16 & $-0.53^{a}$ & $0.30^{c}$ & -0.19 & 0.06 & -0.22 & $0.31^{c}$ & $0.49^{b}$ & - & - & - & - \\
\hline & (53) & (53) & $(53)$ & $(50)$ & $(49)$ & (53) & $(46)$ & $(45)$ & $(47)$ & & & & \\
\hline 11 Functional limitations t1 & $(234)$ & $(234)$ & $(234)$ & $(224)$ & $(216)$ & $(230)$ & $(209)$ & $(214)$ & $(105)$ & (53) & & & \\
\hline \multirow[t]{2}{*}{12 Functional limitations t2 } & 0.14 & $0.31^{a}$ & $-0.21^{\mathrm{c}}$ & 0.14 & 0.05 & -0.01 & -0.19 & $0.21^{c}$ & $0.43^{a}$ & $0.37^{b}$ & $0.78^{a}$ & - & - \\
\hline & $(134)$ & $(134)$ & $(134)$ & $(128)$ & $(125)$ & $(134)$ & $(121)$ & $(117)$ & (105) & (49) & $(134)$ & & \\
\hline 14 Moved to care home ${ }^{d}$ & (83) & (83) & (83) & (79) & (79) & (83) & (75) & (73) & $(60)$ & (49) & (83) & (82) & (65) \\
\hline
\end{tabular}

\footnotetext{
${ }^{\mathrm{a}} p<0.001,{ }^{\mathrm{b}} p<0.01,{ }^{\mathrm{c}} p<0.05,{ }^{\mathrm{d}}$ Compared to those participating in the study and living in community between times 1-3.
} 
Supplementary Table 1. The distributions and comparisons (multinomial regressions) of the baseline characteristics among people with dementia who participated in all three waves, moved to care homes and dropped out of ELSA.

\begin{tabular}{|c|c|c|c|c|c|c|c|}
\hline \multirow[b]{2}{*}{$\begin{array}{l}\text { Baseline } \\
\text { characteristics }\end{array}$} & \multirow[b]{2}{*}{$n$} & \multicolumn{4}{|c|}{$\begin{array}{l}\text { Distributions } \\
M(S D) / \%\end{array}$} & \multicolumn{2}{|c|}{$\begin{array}{l}\text { Multivariable multinomial }(n=181) \\
\text { Participated in all three waves vs. }\end{array}$} \\
\hline & & $\begin{array}{l}\text { Participated in all } \\
\text { three waves (a) }\end{array}$ & $\begin{array}{l}\text { Moved to care } \\
\text { home (b) }\end{array}$ & $\begin{array}{l}\text { Dropped } \\
\text { out (c) }\end{array}$ & $\begin{array}{l}\text { Bivariate } \\
\text { multinomial }\end{array}$ & $\begin{array}{l}\text { Moved to care } \\
\text { home }\end{array}$ & Dropped out \\
\hline Female & 234 & 44 & 69 & 52 & a vs. $b^{*}$ & 0.84 & 0.08 \\
\hline Age & 234 & $71.0(10.0)$ & $81.2(5.9)$ & $80.7(8.4)$ & $\begin{array}{l}\text { a vs. } b^{* * *} \\
\text { a vs. } c^{* * *}\end{array}$ & $0.14^{* *}$ & $0.11^{* * *}$ \\
\hline Has partner & 234 & 75 & 54 & 54 & a vs. $c^{*}$ & 0.30 & -0.54 \\
\hline No qualification & 224 & 35 & 48 & 52 & a vs. $c^{*}$ & 0.53 & 0.58 \\
\hline Routine occupation & 216 & 49 & 34 & 45 & & -0.96 & 0.09 \\
\hline Home owner & 230 & 70 & 77 & 76 & & -0.14 & 0.20 \\
\hline Wealth quintile & 209 & $2.7(1.4)$ & $2.5(1.2)$ & $2.8(1.2)$ & & -0.23 & 0.24 \\
\hline Unmet need & 214 & $2.1(1.9)$ & $1.6(1.4)$ & $2.2(2.3)$ & & $-0.36^{*}$ & -0.25 \\
\hline Functional limitations & 234 & $6.8(5.9)$ & $12.5(5.7)$ & $12.5(7.0)$ & $\begin{array}{l}\text { a vs. } b^{* *} \\
\text { a vs. } c^{* * *}\end{array}$ & $0.19^{* *}$ & $0.22^{* * *}$ \\
\hline
\end{tabular}


$\mathrm{M}=$ mean, $\mathrm{SD}=$ standard deviation, ${ }^{* * *} p<0.001,{ }^{* *} p<0.01,{ }^{*} p<0.05$. The table shows e.g. that a higher proportion (69\%) of those who moved to care home were women compared to those who participated in all three waves (44\% were women) when looking at the these two variables only (bivariate multinomial regression). However when all baseline characteristics were added this difference was not significant (multivariable multinomial regression). 
Table 3. Standardized direct and indirect effects (Standard Error) on change in unmet need between time 1 (ELSA wave 6 or 7 ) and time 3 (ELSA wave 8 or 9) among people with dementia in ELSA.

\begin{tabular}{|c|c|c|c|c|}
\hline Parameter & Direct effect & $\begin{array}{l}\text { Indirect effect via } \\
\text { level of functional } \\
\text { limitations }\end{array}$ & $\begin{array}{l}\text { Indirect effect via } \\
\text { level of unmet } \\
\text { need }\end{array}$ & $\begin{array}{l}\text { Total indirect } \\
\text { effect }\end{array}$ \\
\hline Female & $-0.10(0.077)$ & $0.01(0.025)$ & $0.12(0.053)^{*}$ & $0.13(0.055)^{*}$ \\
\hline Age & $0.07(0.075)$ & $0.11(0.042)^{\star *}$ & $-0.01(0.059)$ & $0.10(0.069)$ \\
\hline Has partner & $-0.38(0.093)^{\star * *}$ & $-0.01(0.029)$ & $0.11(0.061)$ & $0.10(0.064)$ \\
\hline No qualification & $0.18(0.147)$ & $-0.01(0.029)$ & $0.08(0.067)$ & $0.07(0.064)$ \\
\hline Routine occupation & $-0.20(0.146)$ & $0.04(0.031)$ & $-0.08(0.067)$ & $-0.04(0.064)$ \\
\hline Home owner & $0.01(0.091)$ & $0.01(0.026)$ & $0.08(0.083)$ & $0.09(0.074)$ \\
\hline Wealth quintile & $0.04(0.102)$ & $-0.10(0.042)^{*}$ & $0.15(0.073)^{*}$ & $0.05(0.075)$ \\
\hline
\end{tabular}

${ }^{* * *} p<0.001,{ }^{* *} p<0.01,{ }^{*} p<0.05$. For instance, a higher wealth quintile contributed to a $15 \%$ faster increase in unmet needs over the four-year period when the effect of initial level of unmet need on the change in unmet need (a higher increase among those with lower levels of unmet needs, i.e. fanning in) was taken into account. The indirect paths were calculated from the paths shown in Figure 1: wealth on intercept unmet need $(-0.29)$ and intercept unmet need on slope unmet need $(-0.44)$ by multiplying their standardized estimates: $-.21^{*}-0.70=0.15$. At the same time a higher wealth quintile also contributed indirectly through the level of functional limitation, in this case reducing the rate of change in unmet needs about $10 \%$ over the follow-up. The total indirect effect of wealth on the change in unmet need is $-0.10+0.15=0.05$, indicating no overall indirect effect when the contributions through the levels of unmet need and functional limitations were taken into account. 


\section{Figure captions}

Figure 1. Latent Growth Curve for unmet need and functional limitations among people with dementia in ELSA three successive waves $(n=234)$. I =intercept, $S=$ slope for unmet need (unmet) and functional limitations (func), all covariates from time 1 (ELSA wave 6 or 7 ), unstandardized path estimates and standard errors (in parathesis) are shown, bold arrows illustrate mediation through the level (intercept). ${ }^{*} p<0.05,{ }^{* *} p<0.01,{ }^{* * *} p<0.001$. Model fit: $\chi^{2}=40.30, \mathrm{df}=22, p=0.010, \mathrm{CFI}=$ 0.94, RMSEA $=0.060$, SRMR $=0.061$

Figure 2. The estimated change in unmet needs by baseline level of functional limitations. The estimates for the 'average' group are from the latent growth curve (Figure 1), and for the 'low' and 'high' groups from the same latent growth curve fitted in two groups simultaneously (multiple group model). The figure shows that the increase in unmet needs is faster among those who have higher levels of functional limitations at baseline. time $1=$ ELSA wave 6 or 7 , time $2=$ ELSA wave 7 or 8 , time $3=$ ELSA wave 8 or 9

Figure 3. The estimated change in unmet needs by baseline level of unmet needs. The estimates for the 'average' group are from the latent growth curve (Figure 1), and for the 'low' and 'high' groups from the same latent growth curve fitted in two groups simultaneously (multiple group model). The figure shows that the increase in unmet needs is faster among those who have lower levels of unmet needs at baseline. time $1=$ ELSA wave 6 or 7 , time $2=$ ELSA wave 7 or 8 , time $3=$ ELSA wave 8 or 9 . 
Figure 4. The estimated change in functional limitation by baseline level of unmet needs and functional limitations. The estimates are from the latent growth curve (see Figure 1) which was fitted in the subgroups simultaneously (multiple group model). The figure shows that functional limitations increase faster when the unmet needs are high initially (the darker colour lines compared to lighter colour lines) in those with low or average level of functional limitations initially (dotted and solid lines). When functional limitations are higher (broken lines) the pattern of change in functional limitations is similar among those with low and high unmet needs initially. 


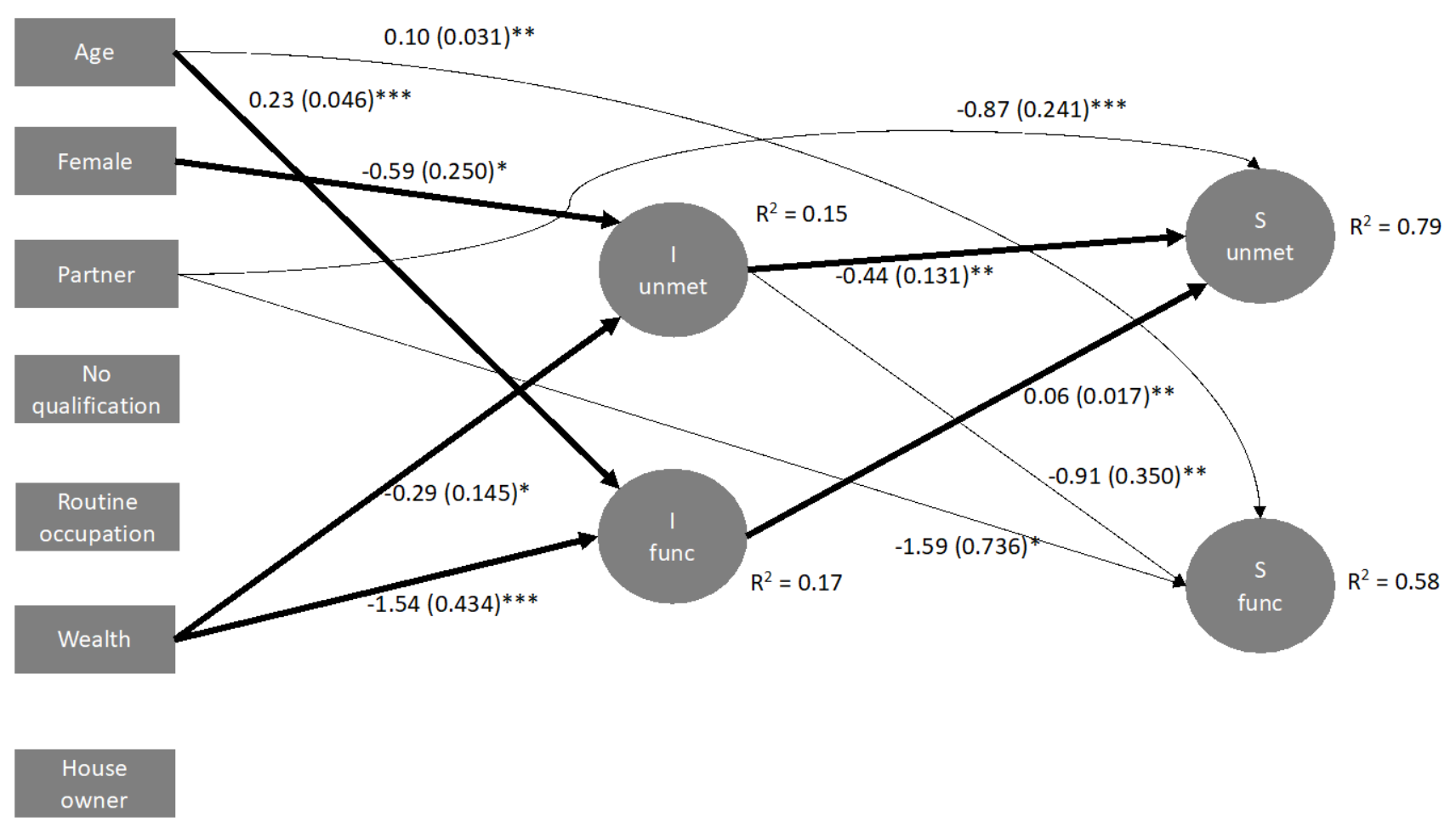




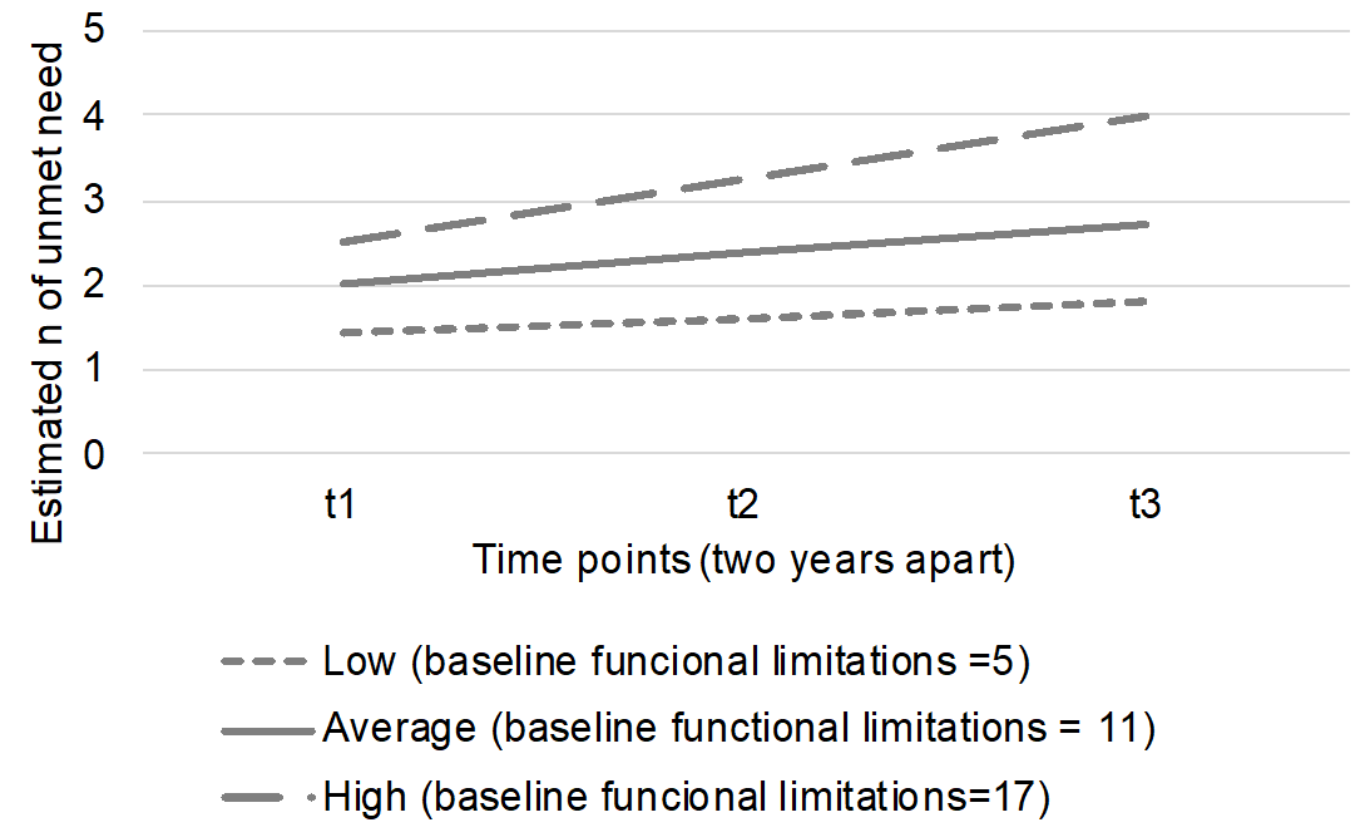




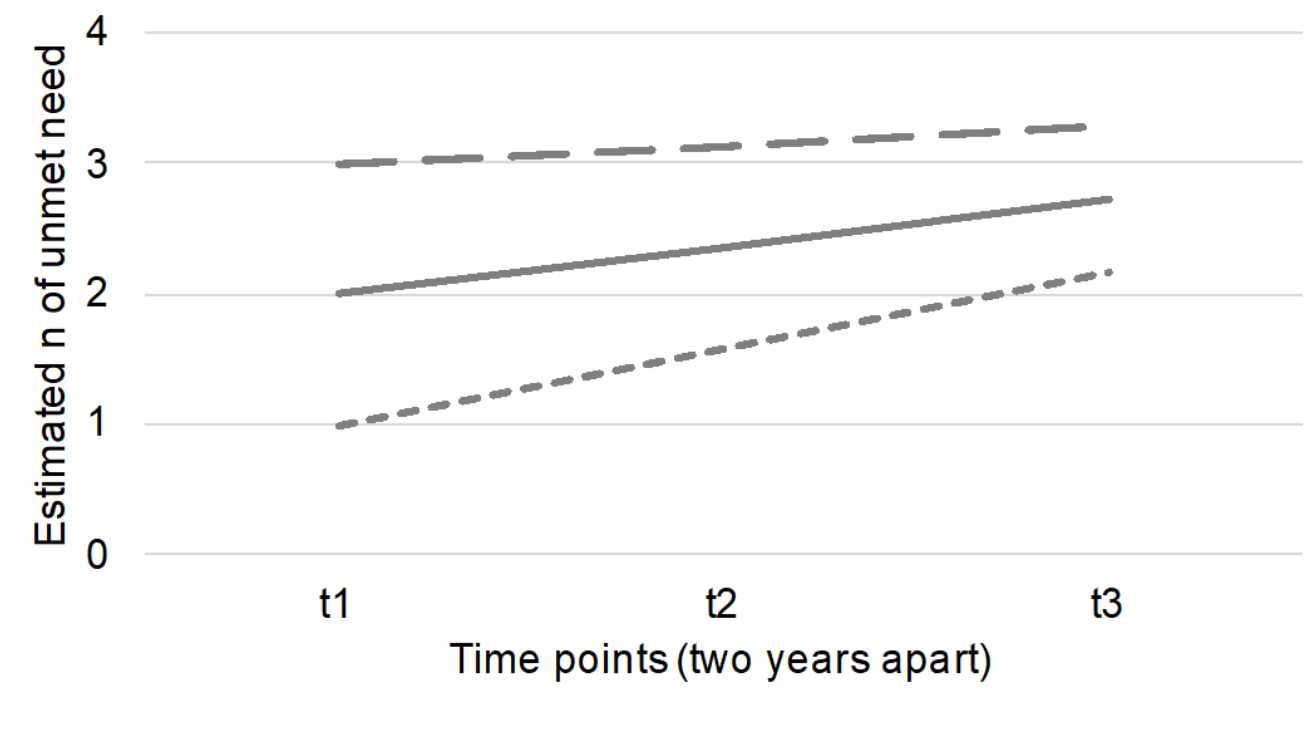

---One - Two - Three

Number of unmet needs at baseline 


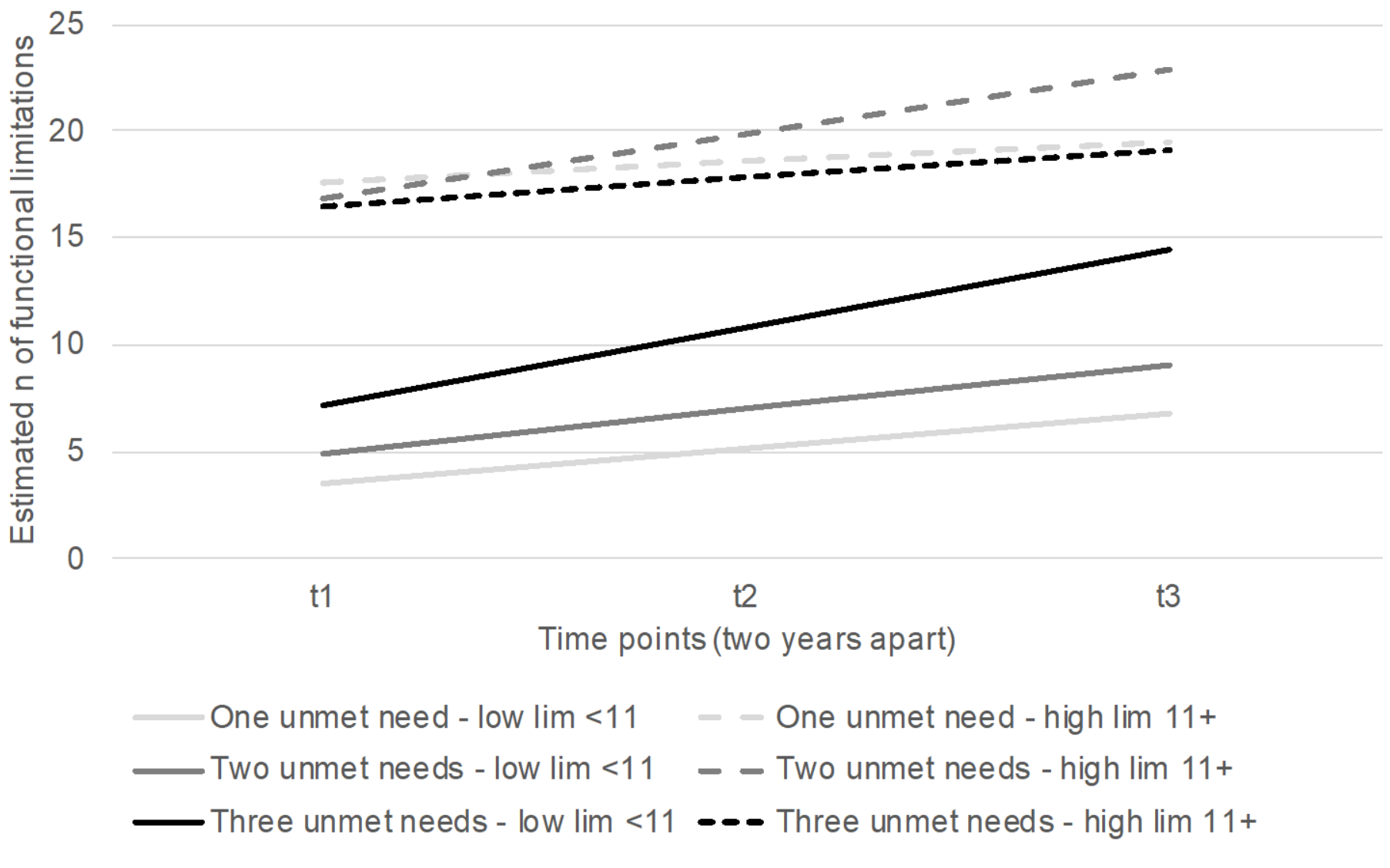


Supplementary Table 1. Activities of Daily Living (ADLs), Instrumental Activities of Daily Living (IADLs) and mobility items in ELSA.

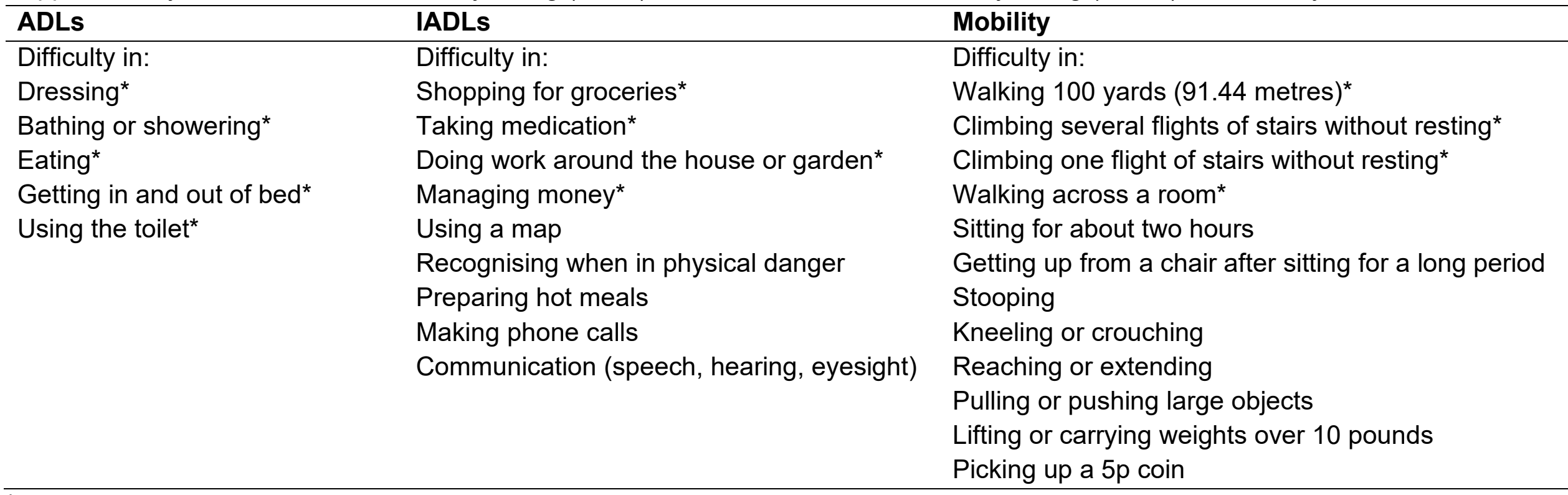

* Used in coding unmet need 
Supplementary Table 2. Descriptive results for unmet need related to mobility, activities of daily living (ADL) and instrumental activities of daily living (IADL) at time 1, 2 and 3 (ELSA waves 6, 7 and 8 or 7,8 and 9) among people with dementia.

\begin{tabular}{|c|c|c|c|c|}
\hline & $n$ & $\begin{array}{l}\text { Observed } \\
M(S D)\end{array}$ & $\begin{array}{l}\text { LGC Model } \\
\text { Intercept }\end{array}$ & $\begin{array}{l}\text { LGC Model } \\
\text { Slope }\end{array}$ \\
\hline Unmet need mobilitya & & & $1.33(0.09)^{* * *}$ & $0.50(0.16)^{* *}$ \\
\hline time 1 & 215 & $1.4(1.3)$ & & \\
\hline time 2 & 106 & $1.4(1.4)$ & & \\
\hline time 3 & 53 & $1.6(1.3)$ & & \\
\hline Unmet need $\mathrm{ADL}^{\mathrm{b}}$ & & & $0.33(0.05))^{* * *}$ & $-0.04(0.35)$ \\
\hline time 1 & 215 & $0.3(0.8)$ & & \\
\hline time 2 & 106 & $0.4(0.8)$ & & \\
\hline time 3 & 53 & $0.3(0.8)$ & & \\
\hline Unmet need IADL ${ }^{c}$ & & & $0.38(0.05)^{* * *}$ & $0.41(0.43)^{* *}$ \\
\hline time 1 & 215 & $0.3(0.6)$ & & \\
\hline time 2 & 106 & $0.4(0.7)$ & & \\
\hline time 3 & 53 & $0.6(0.9)$ & & \\
\hline
\end{tabular}

Note. The intercept and slope for unmet need in mobility, ADLs and IADLs tested separately in three LGC models. ${ }^{\text {a Number of }}$ mobility difficulties (max 4 items) in which does not receive help. ${ }^{b}$ Number of ADL difficulties (max 5 items) in which does not receive help. ${ }^{c}$ Number of IADL difficulties ( $\max 4$ items) in which does not receive help $M=m e a n, S D=s t a n d a r d ~ d e v i a t i o n$, LGC=Latent Growth Curve. ${ }^{*} p<0.05,{ }^{* *} p<0.01,{ }^{* * *} p<0.001$ 


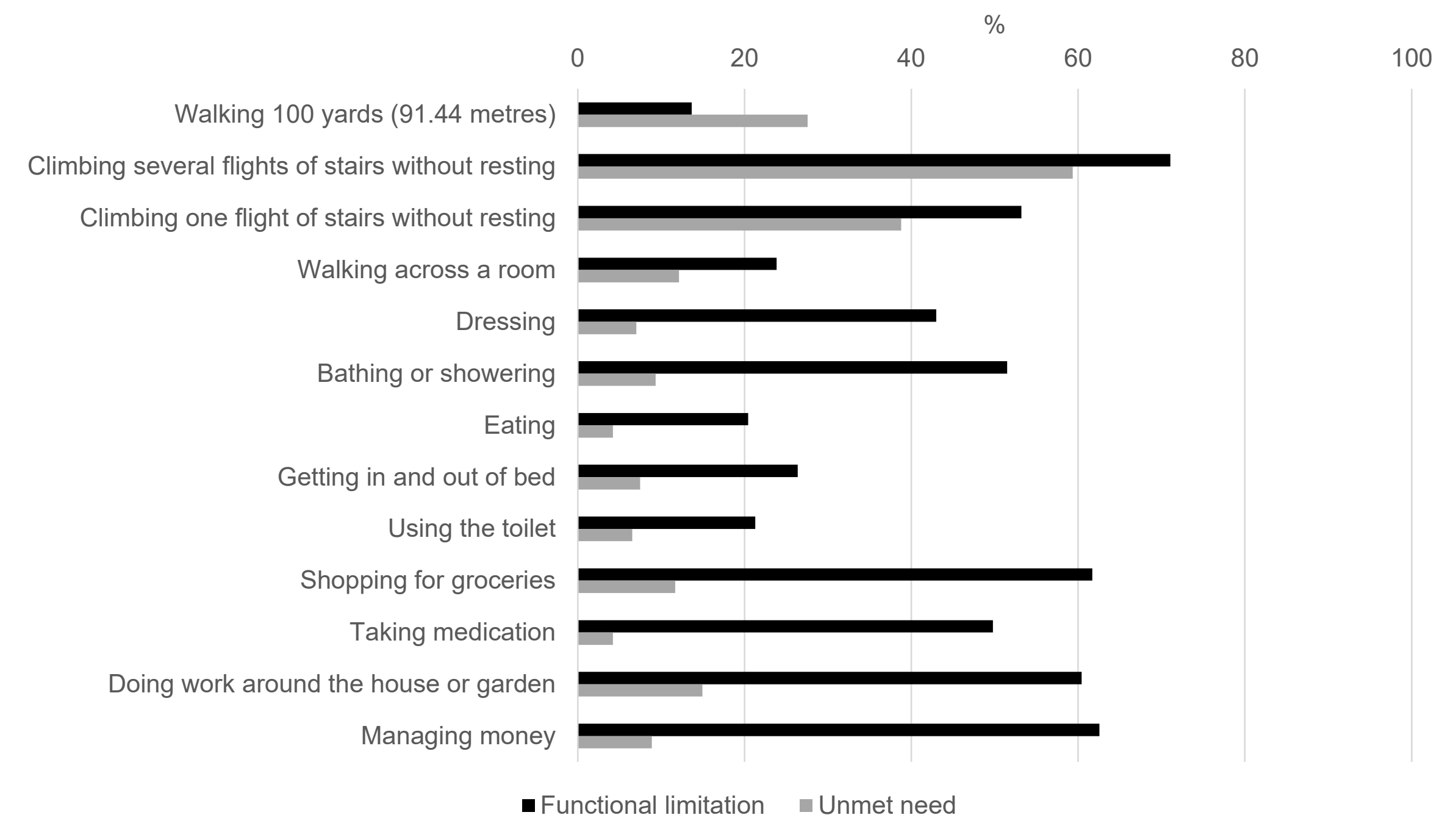

Supplementary Figure 1. Proportions of functional limitations $(n=234)$ and unmet need $(n=214)$ in 13 tasks in time 1 (ELSA wave 6 or 7). 


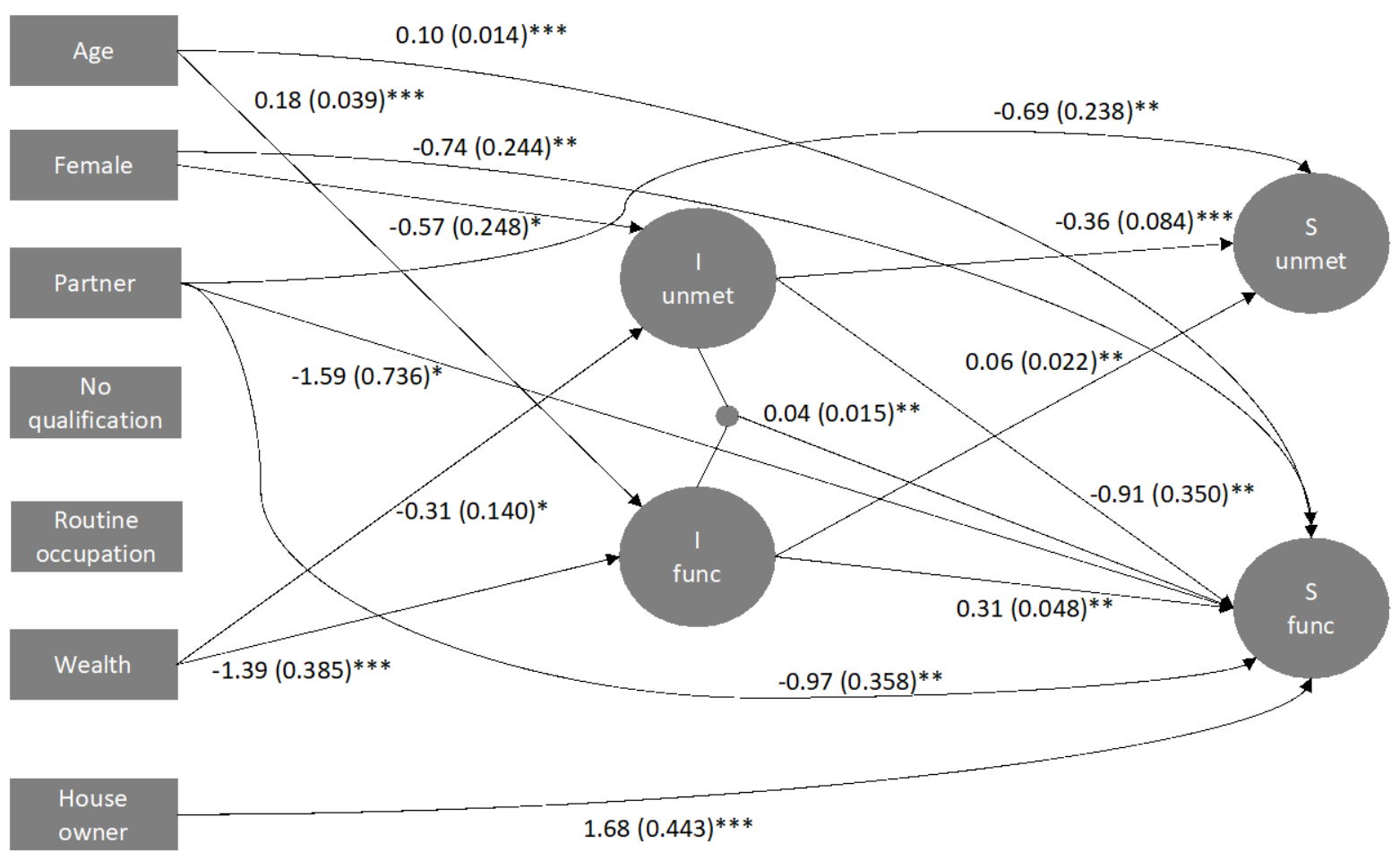

Supplementary Figure 2. Latent Growth Curve for the interaction between baseline unmet need and functional limitations on change in functional limitations among people with dementia in ELSA three successive waves $(n=234)$. I =intercept, S = slope for unmet need (unmet) and functional limitations (func), all covariates from time 1 (ELSA wave 6 or 7 ), unstandardized path estimates and standard errors (in parathesis) are shown. ${ }^{*} p<0.05,{ }^{* *} p<0.01,{ }^{* * *} p<0.001$. 


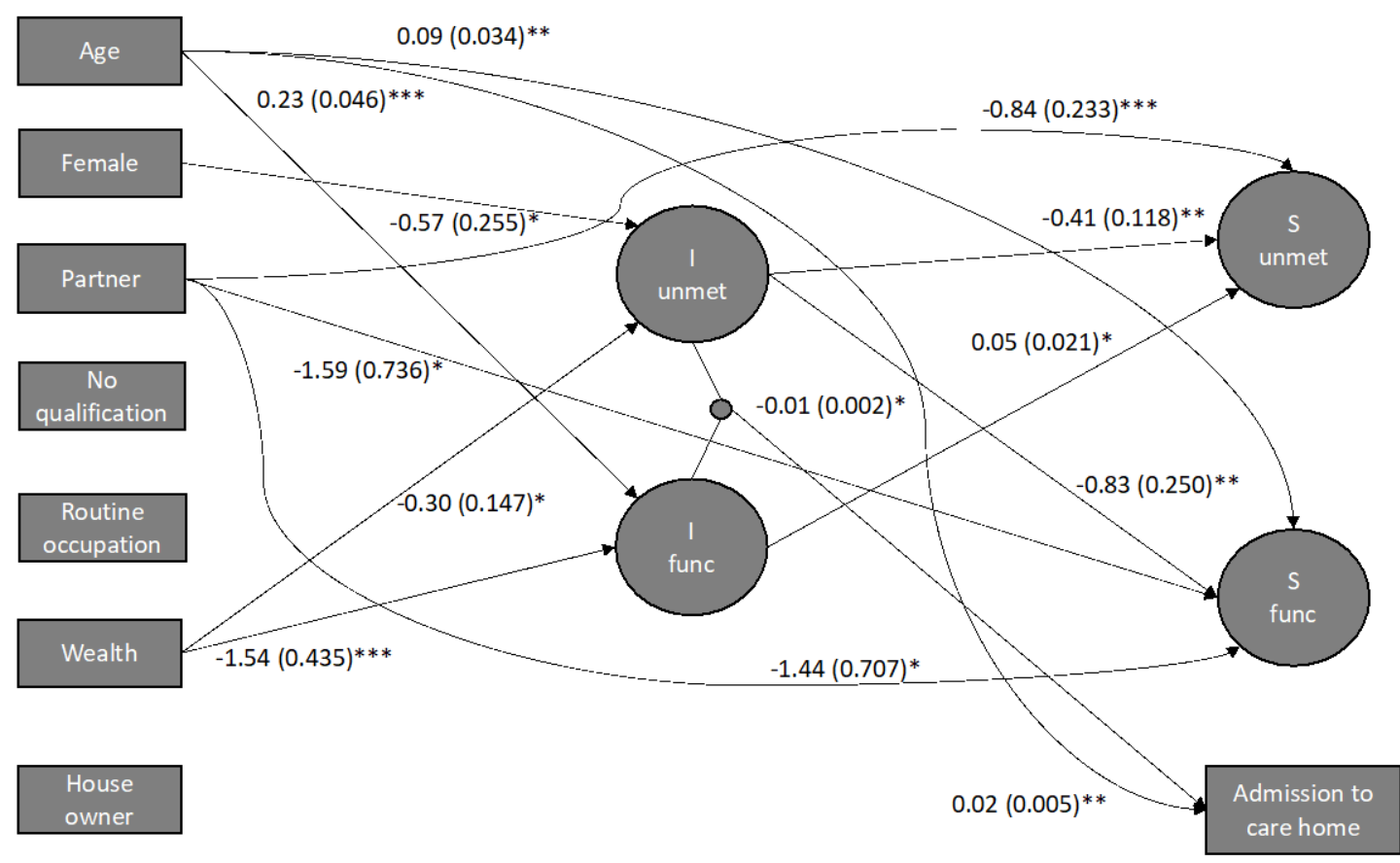

Supplementary Figure 3. Latent Growth Curve for the interaction between baseline unmet need and functional limitations on move to care home among people with dementia in ELSA three successive waves $(n=234)$. I =intercept, $S=$ slope for unmet need (unmet) and functional limitations (func), all covariates from time 1 (ELSA wave 6 or 7 ), unstandardized path estimates and standard errors (in parathesis) are shown. ${ }^{*} p<0.05,{ }^{* *} p<0.01,{ }^{* * *} p<0.001$. 


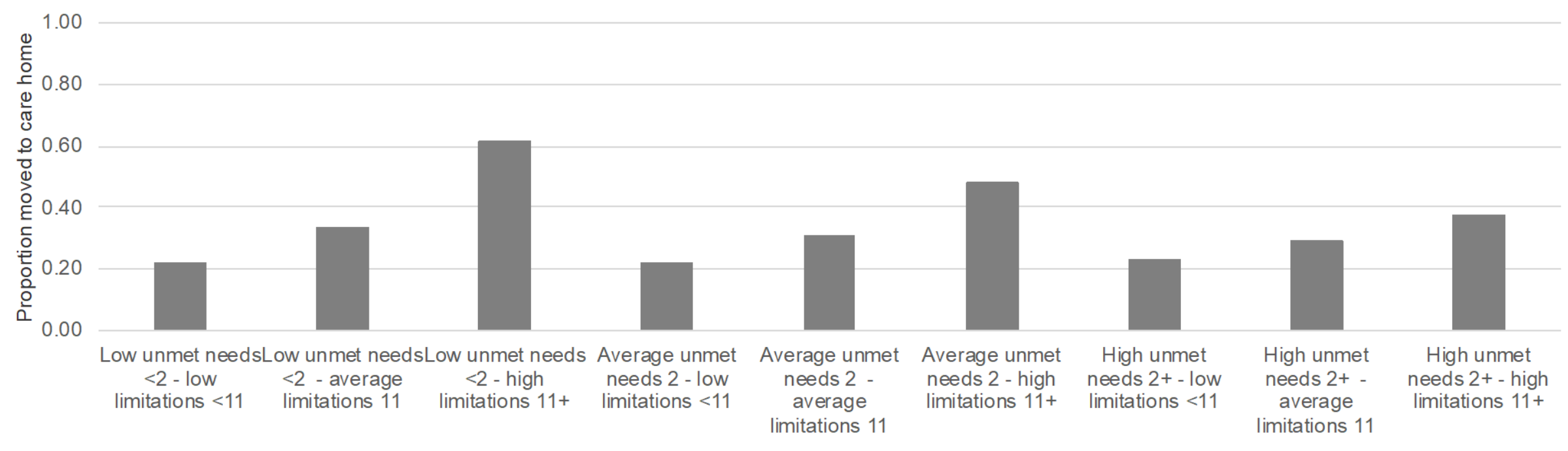

Supplementary Figure 4 . The proportions of people with dementia who moved to care home in three consecutive waves $(6,7$ and 8 or 7, 8 and 9) of ELSA by the initial level of unmet needs and functional limitations. The estimates are from the latent growth curve (see Figure 1) which was fitted in the subgroups simultaneously (multiple group model). 